\title{
Enhancing Learning Through Continuous Improvement: Case Studies of the Toyota Production System in the Automotive Industry in South Africa
}

Keiji Ishigame

\section{INTRODUCTION}

Learning is one of the keys to sustained growth. Stiglitz and Greenwald (2014) insist that, compared to developed countries, developing countries have gaps in their knowledge, and learning is important in closing such gaps. With many firms in developing countries situated below global best practice levels, learning improves productivity as they catch up.

Learning also unlocks a company's potential and promotes its development as a global firm. Toyota is a global automotive manufacturer well known for its efficient production system (Womack et al. 1990; Monden 2011). Toyota has learned from global best practices to improve its productivity. In 1945, Toyota estimated that its productivity was at one-tenth of global best practice (Fujimoto 1999). It learned from US car makers ${ }^{1}$ and developed its own production system, the so-called Toyota Production System (TPS) (Ohno 1998). The system aims at "making the vehicles

K. Ishigame $(\bowtie)$

Partnership Program Division, Yokohama Center, Japan International

Cooperation Agency, Tokyo, Japan

e-mail: Ishigame.Keiji@jica.go.jp

(C) The Author(s) 2020

A. Hosono et al. (eds.), Workers, Managers, Productivity, https://doi.org/10.1007/978-981-15-0364-1_9 
ordered by customers in the quickest and most efficient way, to deliver the vehicles as quickly as possible." TPS was established "based on many years of continuous improvements (Kaizen)" (Toyota 2018a). ${ }^{2}$

Toyota also learned by exporting. As Page (Chap. 2) asserts, domestic firms build capabilities through learning. Toyota improved quality and productivity through exports to the US market in the 1960s. Initially, Toyota exported passenger cars but had to suspend exports due to quality-related problems. After developing a vehicle suitable for the US market, Toyota overcame its quality problems (Toyota Jidōsha Kabushiki Kaisha 1988).

Liker (2004) emphasized that TPS is designed to push team members to think, learn, and grow. Through relentless reflection and continuous improvement, a company can become a learning organization, as defined by Senge (1990). Hosono (2016 and chap. 3) concludes that the Toyota Way is similar to the concept of the learning firm explored by Stiglitz and Greenwald (2014).

Kaizen was first introduced into Asian countries through the business activities of Japanese companies and Japanese official development assistance programs. It was extended to Latin America and the Middle East, before finally being implemented in Africa (Ohno et al. 2009). In Ghana, based on a randomized experiment, it was demonstrated that basic-level management training including Kaizen improves business practices and performance (Mano et al. 2012). Ethiopia has adopted a comprehensive approach to introducing Kaizen nationwide at both policy and business levels (Ohno 2014; Shimada 2015). However, research measuring the impact of Kaizen in Africa is limited, with few case studies of specific firms apart from Kaplinsky's (1995) case study from Zimbabwe. Yan and Makinde (2011) argued that continuous improvement plays a significant role in promoting development process of new products in small- and medium-sized enterprises (SMEs) in South Africa; however, no study has ever tried to analyze Kaizen in TPS with local firms in Africa.

This chapter aims to measure the impact of Kaizen, known as TPS in South Africa, where Japan International Cooperation Agency (JICA) projects have been implemented. The objective of the research is to investigate how Kaizen can enhance the competitiveness of automotive suppliers in South Africa. It also aims to assess ways that Kaizen supports enhanced learning in companies. The research questions are as follows: 
1. Does Kaizen enhance the competitiveness of the suppliers?

2. Does the effectiveness of Kaizen differ among suppliers? What factors contribute to this? and

3. Does Kaizen have a positive impact on learning?

Section 2 briefly outlines the automotive industry in South Africa and the JICA project. Section 3 presents the research methodology, while Sect. 4 presents the case studies. Section 5 discusses the study findings before conclusions are presented in Sect. 6.

\section{Automotive Industry in South Africa And JiCA PROJECT}

\subsection{Automotive Industry in South Africa}

The automotive industry comprises the largest manufacturing sector in South Africa, contributing 6\% to the country's gross domestic product (GDP) and supporting 113,000 jobs (DTI 2018). Annual production is 599,004 vehicles, with more than $60 \%$ exported. The industry is composed of six major vehicle assemblers, thirteen assemblers of heavy and medium commercial vehicles, and approximately 360 component manufacturers (ASCCI 2017).

The industry in South Africa has developed since Ford and General Motors started operations in the 1920s (Black 2001). After the end of apartheid in 1994, the South African government incorporated the automotive industry into development policy to promote exports (Black 2017). The Motor Industry Development Program (MIDP) (1995-2012) and Automotive Production and Development Program (APDP) (20132020) have provided incentives to promote local production and exports.

The MIDP was aimed at supporting the development of the local vehicle assembly and component industries, with emphasis on improving the industry's exporting prospects. It implemented the following policies for economic liberalization and promotion of exports. First, local content provisions for domestic vehicle assembly were abolished. Protection tariffs were reduced from $115 \%$ for completely built-up units (CBUs) and completely knocked-down (CKD) to $40 \%$ and $30 \%$ by 2002 . These were further reduced to $30 \%$ and $25 \%$, respectively, by 2007 , and finally to $25 \%$ and $20 \%$ in 2012. Secondly, original equipment manufacturers (OEMs) receive a duty-free allowance for domestic production and component manufacturers to obtain duty credits from exporting (Comrie et al. 2013). 
The APDP started in 2013 as a follow-up program of the MIDP. The APDP target is the doubling of vehicle production to 1.2 million units by 2020 , with the scale of production emphasized over exports. The program has four key components (AIEC 2013): stable import tariffs, a vehicle assembly allowance, production incentives, and grants delivered through the Automotive Investment Scheme.

\subsection{JICA Project}

In 2015, JICA implemented the Automotive Industry Human Resource Development Project in South Africa. The purpose of the project was to enhance the capacity of human resources in the South African automotive industry and to improve the productivity and quality of suppliers.

Two Japanese experts with rich experience in TPS worked at the Automotive Industry Development Center (AIDC) in South Africa. The experts trained AIDC trainers and provided technical advice to local suppliers along with AIDC trainers. Eight suppliers were selected and received technical advice from the experts and AIDC trainers. ${ }^{3}$ Table 9.1 shows the summery of JICA project companies.

Japanese experts visited suppliers five to ten days per year with AIDC trainers, and the AIDC trainers visited suppliers again separately every two weeks on average. AIDC trainers and representatives from the suppliers joined a ten-day study tour to Japan to understand Kaizen. Box 9.1 shows the steps in the assistance provided to suppliers.

\section{Box 9.1 Steps in Assistance to Suppliers}

[1st Stage: 5S and Understanding Current Conditions]

1. Understanding material and information flows

- Understanding production systems

- Finding problems and outstanding issues

2. Thorough $5 \mathrm{~S}$

3. First in, first out (FIFO)

[2nd Stage: Making Production Management Tool]

1. Prepare operation standards

- Operation manuals 
- Quality check standards

- Machine maintenance manuals

2. Prepare abnormality management tools

- Operator placement map

- Production performance board

- Defect parts control

3. Prepare key performance indicators (KPI)

\section{[3rd Stage: Kaizen Activity]}

1. One-piece flow, SEIRYUKA (rectification of production flow)

2. Pull system, Fill-up system (Kanban system)

3. Heijunka production

4. Standardized work

5. Motion Kaizen, multi-skilled operator

Source: Project document modified by Author

\section{Box 9.2 Glossary of Kaizen Activities in the Project}

- First In, First Out (FIFO) is an inventory management method: the earliest items delivered are the first used. The items must be utilized before they start deteriorating.

- One-piece flow is the ideal state where parts are manufactured one at a time, and flow throughout manufacturing. It is a key concept of TPS.

- Kanban system is a system that conveys information between processes and automatically orders parts as they are used up. Every item or box of items that flows through the production process carries its own Kanban.

- Heijunka production is a technique for leveling fluctuations in performance within the assembly line. It facilitates Just-In-Time (JIT) production and smooths out production in all departments.

Source: Toyota Production System Glossary, ${ }^{4}$ modified by Author 
Table 9.1 Summary of JICA project companies

\begin{tabular}{llll}
\hline Company & Number of staff & Tier & Capital (local/foreign) \\
\hline A & 240 & Tier 1 & Local \\
B & 147 & Tier 1 & Local \\
C & 242 & Tier 1 & Local \\
D & 45 & Tier 2 & Local \\
E & 103 & Tier 1 and Tier 2 & Local \\
F & 509 & Tier 1 & Local \\
G & 118 & Tier 1 & Local \\
H & 18,885 & Others & Local \\
\hline
\end{tabular}

Source: Interviews and Comrie et al. (2013)

In the first stage of assistance, $5 S^{5}$ is implemented within the target suppliers. $5 \mathrm{~S}$ creates a foundation for well-running equipment and proper material management. It also helps to identify the current situation and makes problems visible.

In the second stage, a material and information flow diagram (MIFD) is the key to analyzing the current situation and identifying problems. MIFD is a schematic drawing prepared by the AIDC trainer with suppliers that shows the flow of information and materials. It aims at detecting hidden problems in the operation of the industrial process being studied.

In the third stage, JICA experts and AIDC trainers and suppliers discuss and draft possible solutions (Kaizen activities) within the available resources. The activities comprise a wide range of measures that are useful for improving quality and productivity. They are one-piece flow, motion Kaizen, and so on. In other Kaizen projects, the main intervention is $5 \mathrm{~S}$ (see Chaps. 11, 12 and 13 in SME). In this project, $5 S$ is used for creating a foundation to implement other Kaizen activities in the initial stages. International experts advise not only on $5 \mathrm{~S}$ but also on various activities related to the diagnosis of the suppliers. The trainers learned how to analyze problems and find solutions. The project aims to foster skills among trainers to plan and implement Kaizen independently in the auto industry. It can be said that the project supports the learning of advanced Kaizen.

\section{Data And Research Methods}

The research methods used in this study were document reviews and semistructured interviews. The AIDC provided reports on the JICA project, including the performance of Kaizen. These reports were reviewed to 
reveal the numerical results. Interviews and factory visits were conducted with seven suppliers, with one supplier declining due to being fully occupied by intensive work at the assembler's request. Interviews were conducted between September 2017 and October 2017. As Kaizen involves taking into account all levels of people from managers to workers, the interviewees comprised nine managers (managing directors, plant managers, and production managers), seven engineers, two interns, and thirteen operators-thirty-one people in total. Interviews with one AIDC manager, three AIDC trainers, and two JICA experts were also conducted. Interviews with management staff, engineers, and interns were carried out using questionnaires, while those with operators focused on three to four specific questions.

\section{Case Studies}

The project initially covered eight suppliers. With four of these, project activities were suspended due to a lack of company resources, intensive demands by the assemblers, or a change in business focus. Table 9.2 provides a summary of each supplier's progress in the JICA project.

Among the eight target suppliers, Companies A, B, and E are presented here as case studies owing to the considerable impact of Kaizen activities. Table 9.3 outlines the results of interventions in the three companies. In the case of Company A, top management and an engineer played a leading role in promoting Kaizen. A layout change significantly improved quality

Table 9.2 Progress of JICA project companies

\section{Company Progress}

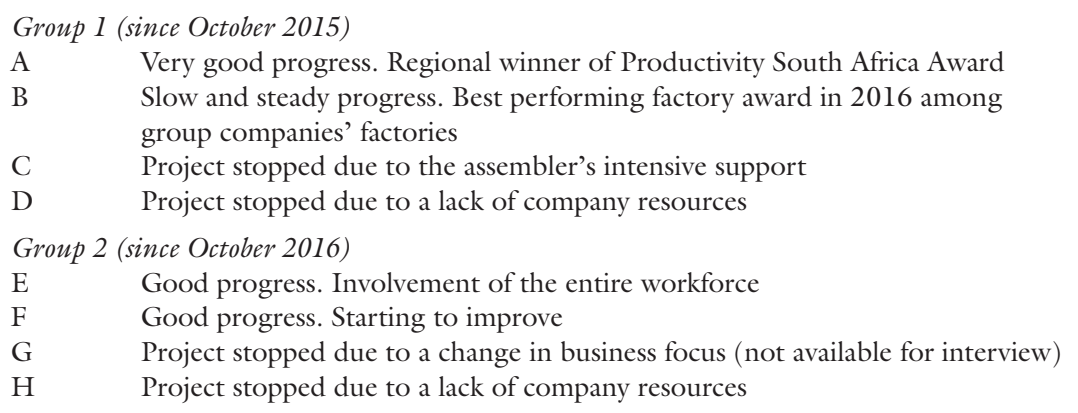


Table 9.3 Summary of three companies’ Kaizen activities

\begin{tabular}{|c|c|c|c|}
\hline Company & $A$ & $B$ & $E$ \\
\hline Product & $\begin{array}{l}\text { Accessory products } \\
\text { (side steps) }\end{array}$ & Floor carpet & $\begin{array}{l}\text { Injection molding } \\
\text { parts }\end{array}$ \\
\hline Project start & October 2015 & October 2015 & October 2016 \\
\hline Main activities & $\begin{array}{l}5 S \text {, Layout change, } \\
\text { One-piece flow }\end{array}$ & $\begin{array}{l}5 S \text {, Top management } \\
\text { workplace walk, Kanban }\end{array}$ & $\begin{array}{l}5 S \text {, One-piece flow, } \\
\text { Milk-Run }\end{array}$ \\
\hline Productivity & $\begin{array}{l}51 \% \text { lead time } \\
\text { reduction }\end{array}$ & OEE ${ }^{a}: 78-90 \%$ & $\begin{array}{l}50 \% \text { lead time } \\
\text { reduction }\end{array}$ \\
\hline Profit & $\begin{array}{l}\text { Improved } \\
\text { (turnover up 50\%) }\end{array}$ & $\begin{array}{l}\text { Improved (turnover up } \\
50 \% \text { ) }\end{array}$ & Not improved \\
\hline $\begin{array}{l}\text { Management } \\
\text { commitment }\end{array}$ & Managing director & Managing director & $\begin{array}{l}\text { Managing director \& } \\
\text { production executive }\end{array}$ \\
\hline $\begin{array}{l}\text { Resource } \\
\text { allocation (HR) }\end{array}$ & Intern $\rightarrow$ Engineer & Engineer & Engineer \\
\hline $\begin{array}{l}\text { Resource } \\
\text { allocation } \\
\text { (budget) }\end{array}$ & $\begin{array}{l}\text { Utilize internal } \\
\text { resources }\end{array}$ & US $\$ 18,453^{\mathrm{b}}$ & Limited \\
\hline Repeated training & Conducted & Conducted & Intensively conducted \\
\hline Learning & Positive & Positive & Very positive \\
\hline
\end{tabular}

Source: Author's survey

aOEE: Overall Equipment Effectiveness. OEE is a framework for measuring the efficiency and effectiveness of a process, by breaking it down into three constituent components: quality (only good parts), performance (as fast as possible), and availability (no stop time)

b250,000 ZAR = US $\$ 18,453.9$ (US $\$ 1=13.5473 \mathrm{ZAR}$, exchange rate on October 1,2017 )

and productivity, and sales and profits also improved. In the case of Company B, commitments and actions of both top management and an engineer led to gradual improvements. In the case of Company E, Kaizen is practiced by the entire workforce under the commitment and involvement of top management. Introduction of a one-piece flow system brought obvious improvements in quality and productivity in the short term. The following case studies provide further details regarding Kaizen activities.

\subsection{Company $A$}

\subsubsection{Company Profile}

Company A was founded in 1960 and has 240 employees. The company produces automotive accessory products, including nudge bars, bumper replacements, side steps, and so on, selling them to US, Japanese, and 
German manufacturers. As a small business producing low volume but highly diverse parts, the company was motivated to join the JICA project because it saw the need to boost working culture and processes.

\subsubsection{Process}

The managing director has a strong commitment to the Kaizen process. He assigned an engineer, an intern from universities of technology. The engineer learned specific Kaizen methods from Japanese experts and AIDC trainers and implemented them. The company initially conducted $5 \mathrm{~S}$ activities. After $5 \mathrm{~S}$ was carried out, problems were identified by MIFD and an optimized layout was drawn up. AIDC trainers and the engineer drafted the MIFD. The MIFD showed problems in the material and information flow, with extended distances to be traveled, causing significant stagnation. In the styling bar production line, the process flow was not established properly, and the layout was not optimized. The average units-per-day production did not meet customer demand. The company decided to change its factory layout based on recommendations from experts and AIDC trainers. The managing director allocated the budget necessary to change the layout. Large-size machinery was moved into the right places and onepiece flow was implemented. Lead times were shortened and stagnation reduced according to the MIFD analysis. Quality was improved by moving from batch production to one-piece flow as the operator can identify defects during the process. The main outcomes are shown in Table 9.4. Motion was improved and cycle time and work in process were reduced.

Before Kaizen was introduced, processes were scattered around the factory. When one process was completed, work in process piled up on the floor. It was then moved to a rack for delivery to the next process. Operators concentrated on one specific process and did not multitask.

Table 9.4 Outcomes of optimizing layout (styling bar improvements)

\begin{tabular}{ll}
\hline Action (optimized layout) & Improvement (\%) \\
\hline Walking distances while carrying styling bar & $83.3 \%$ motion improvement \\
Total cycle time & $51.9 \%$ more efficient \\
Work in process (WIPa) & $67.6 \%$ reduction \\
Number of required operators & $66 \%$ reduction \\
\hline
\end{tabular}

Source: Presentation material drafted by AIDC and modified by Author

${ }^{a}$ Work in process is partially completed goods, parts, or subassemblies that are no longer part of the raw materials inventory and not yet part of the finished products inventory 
After the layout changed, the process has become a line and work in process is no longer placed directly on the floor but is put on a newly crafted rack ready for the next process. A single operator can undertake several tasks at the same point. Walking for delivery has been eliminated and the volume of work in process has been reduced. In all, the number of required operators and total cycle time has been reduced. The company utilized scrap steel to make racks and trollies. Racks were designed and fabricated for specific parts. Transportation trollies were also made and double handling was eliminated, improving productivity.

When the engineer faced difficulties, he reported them to the managing director, who provided solutions and advice in a timely manner. After the positive impact of the JICA project was observed, the company decided to accept five interns-students from universities of technology studying industrial engineering. The engineer trained them to expand Kaizen activities in the factory. In addition, all three production managers were sent to college to take a one-year course in industrial engineering.

\subsubsection{Results}

Results were very positive: monthly turnover increased by $50 \%$ and profits improved. After the company changed (optimized) its layout based on the problem analysis, it received a Productivity Award, the second in South Africa. Based on MIFD analysis, the layout changes improved quality and productivity.

\subsubsection{Challenges}

Changing the mindset of employees is arduous. They do not accept change easily and often mistakenly believe that improvement could increase their workloads or result in loss of their jobs. Kaizen training did promote a change in this mindset. However, it was not only the operators who needed repeated training to sustain Kaizen activities but also middle managers. Employees in South Africa are diverse, with multiple languages and cultures. Careful management is required to ensure that employees with a diverse sense of values can work together.

\subsection{Company $B$}

\subsubsection{Company Profile}

Company B was founded in 1998 and has 147 employees. It produces textile-based automotive acoustic and trim components like main floor 
carpets, floor insulators, and trunk trim. The company sells to US and Japanese manufacturers. The motivation to join the JICA project was that the plant manager had a long experience in lean manufacturing and was keen on introducing TPS.

\subsubsection{Process}

The plant manager assigned the industrial engineer to manage the JICA project, with the student interns providing support. First, 5S was conducted, improving productivity. Home positions for all items on the workstation were established. Lines were drawn on the floor to improve visual management. "Gemba" (workplace) walks by management were done regularly with the aim of establishing better $5 \mathrm{~S}$. Weekly audits were standardized and cleaning schedules were established. Accessible cleaning materials were placed at workstations. Before implementing $5 \mathrm{~S}$, material shortages were unpredictable, and therefore production lines ceased operations. When $5 \mathrm{~S}$ was introduced and used to categorize each material, stocks were more easily monitored, and downtimes reduced.

The engineer and AIDC trainer drafted MIFD and identified three problems: (1) no inventory control between processes; (2) excessive work in process; and (3) unbalanced production lines. Ideas to solve issues were discussed and implemented: (1) Kanban; (2) one-piece flow; and (3) standard trolleys.

While Kanban was introduced and Kanban workflow was established, it has not been sustained because operators do not fully understand its necessity. Repeated trainings are required to ensure sustainability.

Training in one-piece flow was also conducted. The AIDC trainer and the industrial engineer showed operators a video about one-piece flow and explained its benefits. While its feasibility was confirmed after a trial, it has not been implemented to date as additional training is required.

Standard trolleys were introduced. This reduced the space needed for products, freeing up space for the accommodation of higher quantities of raw materials, and making products lighter for pushing or pulling.

Management allocated the necessary funds, although budget resources were constrained. When funding was available, it was allocated to Kaizen activities. In one year, about US $\$ 18,453$ was spent on trolleys, signs, demarcation on the shop floor, training, machine automation, and weekend overtime for some activities. 


\subsubsection{Results}

Although Kaizen activities are still being implemented, the impact has been gradual but positive. Over the past two years, with the same headcount, productivity, and quality improved, costs were reduced by about US $\$ 1.6$ million, ${ }^{6}$ and revenue increased by $25 \%$. The lead time has also been shortened in specific production lines and overall equipment effectiveness (OEE) has improved from 78\% to 90\%. The company was given an award as the best performing factory in 2016 among the group's factories.

\subsubsection{Challenges}

Resource allocation remains a challenge. The industrial engineer is a project manager for the JICA project and is the new business manager and industrial engineer for the whole factory. The company accepted two student interns to provide support for the JICA project activities. While financial resources were constrained, management put importance on allocating funds necessary for Kaizen activities.

Changing operator mindsets takes a lot of time and effort as many operators do not necessarily have sufficient knowledge of math and science. The industrial engineer put a lot of effort into mentoring and coaching operators. He organized repeated $5 \mathrm{~S}$ and one-piece flow trainings to operators. Kaizen activities required frequent communications between the industrial engineer and the operators, contributing to better communication among the staff. The factory staff conducts meetings in front of the team board (a visual management whiteboard), and operators are developing the knowledge to carry out operations smoothly.

\subsection{Company $E$}

\subsubsection{Company Profile}

Company $\mathrm{E}$ was founded in 1996. The number of employees is 103. The company produces plastic molded components such as automotive injection molding parts and scuba fins. The company sells them to the US and Japanese manufacturers and other clients. The destruction of their factory by fire provided the motivation for joining the JICA project, as rebuilding the factory provided an opportune time to create a new production system. 


\subsubsection{Process}

The company promoted Kaizen among all levels of staff from managers to operators. The managing director showed a strong commitment, was deeply involved in all Kaizen activities, and monitored progress. The operation's executive and engineer were assigned to implement the JICA project.

The company production system was transformed from batch production to one-piece flow according to the MIFD analysis. 5S was implemented and the MIFD drafted by the AIDC trainer was used to identify problems. Three main problems were detected and countermeasures to solve these problems were proposed: (1) minimizing non-value-added work; (2) establishing the pull production system; and (3) establishing new standardized work. The AIDC trainer and JICA experts conducted training in the one-piece flow system. However, operators insisted that batch production is more productive than one-piece flow. Management and the engineer patiently persuaded them regarding the benefits of onepiece flow. Training programs were provided repeatedly. In each case, management was present and supported the introduction of one-piece flow. Videos were shown to employees on the principles of TPS and onepiece flow.

Managers and supervisors were also trained with operators to understand the benefits of one-piece flow. Simulation games were played to visualize possible improvements. After the training and intense discussions, operators understood the benefits of one-piece flow, and finally agreed that "one-piece flow is amazing because our life is easier." More output can be achieved with less input. Lead time has been reduced significantly and operator loads eased. One-piece flow can also allow inspections for quality into the process. Therefore, the need for four quality inspection staff at final inspection could be eliminated and utilized for other tasks. Managers are also more relaxed and can monitor production progress more easily.

The company minimized non-value-added work. Before Kaizen was implemented, each part was packed in a box, transferred, and unpacked before each process of molding, painting, and assembly. Under the new system such non-value-added work was eliminated and production lead time reduced from 24 hours to 1 hour. Required staff was reduced from four to two people and two staff were reassigned for other tasks. Table 9.5 provides some results from Kaizen activities. Lead times were shortened by eliminating waste in each step of the process. 
Table 9.5 Before and after performance

\begin{tabular}{|c|c|c|c|}
\hline Measure & Before & After & Impact \\
\hline \multicolumn{4}{|c|}{ Introduction of one-piece flow in car cap assembly } \\
\hline Car cap assembly/shift & 190 products & 240 products & $26 \%$ \\
\hline Lead time & 18 hours & 9 hours & $1 / 2$ \\
\hline \multicolumn{4}{|c|}{ Introduction of a milk-run to collect products in each shift } \\
\hline $\begin{array}{l}\text { Lead time for one box to move from molding } \\
\text { section to finished goods section }\end{array}$ & $\begin{array}{l}420 \text { min } \\
(7 \text { hours })\end{array}$ & $30 \mathrm{~min}$ & $1 / 14$ \\
\hline
\end{tabular}

Source: Presentation material drafted by AIDC and modified by Author

\subsubsection{Results}

The results were positive. Tangible improvements in operations were observed. However, sales and profits did not improve because of weak market demand. Participation in the JICA project was for one year, so it took time for the outcomes to indicate improved business performance. Nevertheless, factory-based improvement was considerable.

\subsubsection{Challenges}

As in the previous discussion, significant efforts and continuous training were necessary to persuade operators to overcome their initial resistance and understand the benefits of one-piece flow. The most important factor in success was the commitment of management. Management was highly involved in Kaizen activities and persuaded operators of their value.

The budgetary amount was not important because various activities can be implemented within limited budgets. The company spent a small amount on production tables, demarcating the floor, and fencing operations. On the other hand, allocating time for Kaizen activities is more important. Working harder and training is the key.

\subsection{Suspended Cases}

Clarification of suspended cases is useful for identifying contributing factors to successful implementation of Kaizen. The project activities were suspended in four companies.

\subsubsection{Suspended Cases Due to Assemblers' Intervention}

Two companies had to suspend involvement in the project because the suppliers became fully occupied in intensive work at the assembler's request. The company started to produce parts for a new model of car. 
However, the company did not provide the parts in a timely manner to the assembler, who had to shut down their factory operations as a result. The assembler then intervened in the company's production in order to normalize production and build the new model of car as planned. With the company focusing on responding to the assembler's requests, they were unable to engage in project activities. The company, however, recognized significance of Kaizen through the project implementation. The assembler also promoted Kaizen activities. The company set up a dojo (Kaizen training room) and implemented continuous improvement. The company continued to improve and was able to produce the parts in a timely manner.

Another company also had to respond to assembler's requests due to some operational problems. Therefore, the company stopped the project and declined to participate in interviews for this research.

\subsubsection{Suspended Cases Due to Lack of Management's Commitments} In the other two companies, the management neither took a positive approach to Kaizen nor allocated necessary resources. One company received technical advice from the experts and AIDC trainers and implemented the improvement activities such as $5 \mathrm{~S}$. The production manager and an intern implemented project activities. MIFD analysis discovered that layout change could reduce the lead time and save manpower resulting from the scattering of processes around the factory. AIDC trainers and experts with the production manager proposed the layout change to the top management. As the changes required the movement of large machinery, there were some significant costs involved. Consequently, management did not accept the proposal and project activities were suspended. The production manager and the intern continued to implement Kaizen. Incremental positive results were realized gradually.

The other company implemented $5 S$ activity in its storage areas first. After the completion of the initial $5 S$ activity, activity stagnated. An assigned engineer did not receive proper instructions from management to proceed with the activity. The management did not commit to the project and finally decided to withdraw.

\section{MAJOR Findings}

\subsection{Enbancing the Competitiveness of the Suppliers}

Kaizen has enhanced the competitiveness of all four companies that continued with the project. With only a limited number of participating 
companies and no control group, there is insufficient evidence to determine whether Kaizen enhanced competitiveness. The four companies, however, reduced manufacturing lead time and improved quality and productivity. 5S activity and MIFD analysis helped to identify problems. Layout change according to the MIFD brought improvements in quality and productivity. The companies utilized scrap metal to make specialized racks and trollies for parts. Introduction of one-piece flow facilitated quality checks in each process, improved quality, and reduced manpower needs.

In terms of profitability, only two companies confirmed an improvement. Many companies were not willing to disclose their business performance, such as profits and sales revenue. As a result, the impact on business performance could not be determined. According to the limited answers available, Companies A and B increased their sales and improved their profits after the project started. The other companies did not improve their sales and profits as the automotive market in South Africa has stagnated since the project commencement. In 2015 and 2016, economic growth in South Africa was $1.30 \%$ and $0.28 \%$, respectively. Annual automotive domestic production is 615,658 and 599,004 vehicles (OICA 2018 ). One condition for participation in the project was that there should be no reduction in employees resulting from productivity improvements. Although automotive suppliers in South Africa are under severe circumstances, Companies $\mathrm{A}$ and $\mathrm{B}$ increased profits. In Companies $\mathrm{E}$ and $\mathrm{F}$, improvements in quality and productivity were observed; however, their profits did not increase during the one-year intervention. In the short term, quality and productivity improvements did not result in increased business performance. Profits were affected by market trends and assemblers' business strategies. It can be said that Kaizen works well for increasing a firm's capabilities, especially in the long run.

\subsection{Success Factors of Kaizen Activities}

The impact of Kaizen differed widely among the eight pilot companies. In four of the pilot companies, Kaizen shortened manufacturing lead times and improved quality and productivity. The remaining four companies had to suspend Kaizen activities. Case studies and interviews illustrate that factors contributing to Kaizen implementation are: (1) management commitment; (2) resource allocation; and (3) continuous training. 


\subsubsection{Management Commitment}

In the interviews, $88 \%$ of the respondents identified management commitment as a crucial contributing factor in the successful implementation of Kaizen. Management plays a central role in supervising and implementing Kaizen activities as observed in the case studies. Management has to allocate resources to Kaizen and often needs to coax staff into implementing Kaizen. In Companies A, B, and E, management showed strong commitment to Kaizen activities.

In the two suspended cases, lack of management commitment was significant. In the two companies, management was not fully supportive; therefore, Kaizen activities were suspended. Management needs to understand the benefits of Kaizen and must allocate minimum financial and human resources for Kaizen. In other words, management is required to prioritize productivity and quality improvements in the long term through sufficient expenditure rather than to balk at spending on improvements to maintain current profits.

García et al. (2013) reported that management commitment is a critical success factors for Kaizen. The results of the case studies support their findings. Throughout the project, JICA experts emphasized the need for commitment from management when selecting a pilot company for the introduction of Kaizen. The results of the present study confirm this approach.

\subsubsection{Resource Allocation}

Kaizen needs specific allocations of human and financial resources. A company does not need to hire a production manager with a brilliant background. Management needs only to appoint an engineer and let him/her focus on Kaizen, but with the authority to conduct it. Management should set a reporting time. If they face any problems, management should intervene in a timely manner.

In the case studies of the three companies, the management assigned the engineer and allocated a designated budget to implement Kaizen activities. The management also supported the activities and intervened when necessary. In the JICA project, many companies took on interns from the universities of technology who had studied industrial engineering. Kaizen activities are simple and practical. Sophisticated statistical expertise is not necessarily required. In one of the most successful companies, an intern implements the project activities and is now a permanent member of staff. 
Implementation of Kaizen requires a certain budget, but its size can be flexible and based on a company's resources. As discussed above, companies introduced racks and trollies made of scrap steel. Money was spent on making signs, demarcation of the shop floor, and conducting training. Such costs were limited.

Resource allocations of the eight suppliers differed, although there was no big difference in their business environments. They are in the same auto industry and all companies are locally owned. Companies A and $\mathrm{E}$ faced difficulties in improving profitability during the implementation of Kaizen. Nonetheless, these companies allocated the minimum financial and human resources. Understanding of the management made differences in resource allocation. One company had sufficient sales. Management, however, did not agree on changing the layout because the management put a high value on reducing costs in the short run rather investing in an optimized layout to improve productivity in the long run. Understanding management is important for allocating available resources.

\subsubsection{Continuous Training}

Continuous training, especially for operators, is a contributing factor to successful Kaizen. Kaizen needs continuation, as it is called "continuous improvement." Operators often resist introducing new approaches and insist on continuing with their current ways because it is easier for them. Repeated trainings are required to ensure understanding of Kaizen. Once they understand the benefits, such as the fact that the introduction of a one-piece flow system achieves increased production and reduces work through lower rejection rates, they support implementation. They will continue to implement it because the work is much easier and productive as seen in the case studies. It can be said that Kaizen is friendly to the operator.

\subsection{Impact on Learning}

In interviews with seven suppliers, $88 \%$ of the respondents answered that Kaizen has a positive impact on learning. Even in companies that suspended involvement, management and engineers observed positive impacts on learning.

In the case studies of the three companies, it was observed that Kaizen promotes learning. In Company A, the operators and other individuals 
who did not understand the project's value at the beginning are now seeing the benefits and starting to make suggestions on continuous improvements.

In Company $\mathrm{B}$, the individual mindset is starting to change. Organizational capability grew, and staff was trying to think lean and reduce waste. The plant manager's morning onsite walk led to changes in mindsets, and individuals were motivated and strived more.

In Company E, the management insisted that Kaizen has had a very positive impact and helped the company to become a learning organization. Kaizen culture is starting to be adopted. The adoption of improvements proposed by operators is gradually increasing. Individuals understand the benefits of one-piece flow and this is a win-win situation between the company and its operators.

Through Kaizen activities, operators had opportunities to express their opinions, as Kaizen involves the entire workforce. Before the project was implemented, operators had to follow the instructions and were passive. Once the project began, the operators participated in training and learned about the benefits of $5 \mathrm{~S}$ and one-piece flow. Management and engineers encouraged them to express their opinions. They learned to think by themselves and express their opinions and take the lead in improving factory operations. Conversely, managements and engineers learned not only Kaizen tools but also the importance of involving operators in quality and productivity improvement. They learned how to communicate with operators, listening to their opinions especially carefully. They understood that motivating operators was the key to improvement factories operations. In this way, Kaizen was implemented successfully.

\section{Conclusion}

This study aimed to assess the impact of Kaizen through the introduction of TPS to automotive suppliers in South Africa, as there are few previous studies that have assessed TPS introduction in Africa. First, it was observed that Kaizen enhanced the competitiveness of suppliers through reductions in lead time and improvements in quality and productivity. On the other hand, short-term profitability did not improve. Two suppliers out of the initial eight improved sales and profits. Sales of auto parts are dependent on the market and, in addition, one condition of project participation was no layoffs as a result of project assistance. Second, the impact of Kaizen differed among the suppliers. The contributory factors are management 
commitment, resource allocation, and continuous training. Third, Kaizen had a positive impact on learning, with operators learning how to improve productivity and quality. Managements and engineers insisted that there are positive impacts from creating continuous learning, including in the companies that suspended Kaizen activities. In the case studies, positive impacts on learning were observed.

Through learning Kaizen methods, 5S, MIFD, standardized work, one-piece flow, and so on, factory operators, engineers, and managers learn how to improve productivity and quality. Because Kaizen is smallstep improvements, the operators and engineers acquired information on how to learn and recognized how they themselves can contribute to better factories in the short term. This incremental achievement process also produces a positive desire for a system cycle to make a better workplace.

This review of the project has implications for developing countries. Firstly, governments should utilize Kaizen to develop the private sector. Promoting Kaizen to top management is crucial in the successful implementation and expansion of Kaizen. Secondly, development agencies should select target companies in the Kaizen projects based on careful meetings with management. The project outputs will be less effective if the management do not properly understand the benefits and approach of Kaizen. Thirdly, Kaizen can have a positive impact on employees, especially when learning is emphasized. The operators have the opportunity to learn to improve quality and productivity through participation in Kaizen activities, creating better factories. However, in this research, the number of investigated companies was limited and no control case studies comparisons conducted. Further studies are needed in order to establish the effectiveness of Kaizen and its impacts on learning.

\section{Notes}

1. A Toyota management member visited Ford Motor Company in 1950, where he learned of the employee suggestion system. He adapted the idea in line with the Toyota Way, establishing the Toyota Creative Ideas and Suggestion System (TCISS), and in 1953 set the company slogan "Good Thinking, Good Product," selected through an internal contest. The slogan has been used in Toyota factories around the world (Toyota 2018c).

2. Kaizen is one of the core principles of the Toyota Production System and is the heart of the Toyota Way (Toyota 2018b). 
3. The project supported eight suppliers in October 2017, when interviews were conducted. After that, the project added four more suppliers-in total twelve suppliers.

4. Toyota Production System Glossary, May 31, 2013, https://blog.toyota. co.uk/toyota-production-system-glossary.

5. In the project, it is called $4 \mathrm{~S}$ instead of $5 \mathrm{~S}$ because Shitsuke (discipline), sustaining adherence to rules is not covered in lst stage assistance activity.

6. 22,000,000 ZAR = US $\$ 1,623,939.9$ (US $\$ 1=13.5473 \mathrm{ZAR}$, exchange rate on October 1, 2017).

\section{REFERENCES}

ASCCI. 2017. Automotive Supply Chain Competitiveness Initiative. http://ascci. co.za/sector-profile/.

Automotive Industry Export Council (AIEC). 2013. Automotive Export Manual 2013, South Africa. MIDP, Motor Industry Development Programme, the Track Record 1995-2012. Arcadia, SA: AIEC.

Black, A. 2001. Globalization and Restructuring in the South African Automotive Industry. Journal of International Development 13 (6): 779-796.

- 2017. Trade Liberalization, Technical Change and Firm Level Restructuring in the South African Automotive Component Sector. Institutions and Economies 3 (2): 173-202.

Comrie, D., J. Terreblanche, J. Johnson, and J. Syman. 2013. Industry Mapping and Supplier Diagnostic Report. Gillitts, SA: B\&M Analysts.

Department of Trade and Industry (DTI). 2018. Industrial Policy Action Plan 2018/19-2020/21. Sunnyside, Pretoria: DTI.

Fujimoto, T. 1999. The Evolution of a Manufacturing System at Toyota. New York: Oxford University Press.

García, J.L., D.G. Rivera, and A.A. Iniesta. 2013. Critical Success Factors for Kaizen Implementation in Manufacturing Industries in Mexico. The International Journal of Advanced Manufacturing Technology 68 (1-4): 537-545.

Hosono, A. 2016. Industrial Strategies: Toward a Learning Society for Quality Growth. In Efficiency, Finance, and Varieties of Industrial Policy, ed. A. Noman and J.E. Stiglitz, 306-352. New York: Columbia University Press.

Kaplinsky, R. 1995. Technique and System: The Spread of Japanese Management Techniques to Developing Countries. World Development 23 (1): 57-71.

Liker, J.K. 2004. The Toyota Way. Tokyo: Esensi.

Mano, Y., A. Iddrisu, Y. Yoshino, and T. Sonobe. 2012. How Can Micro and Small Enterprises in Sub-Saharan Africa Become More Productive? The Impacts of Experimental Basic Managerial Training. World Development 40 (3):458-468. 
Monden, Y. 2011. Toyota Production System: An Integrated Approach to Just-inTime. London: CRC Press.

Ohno, T. 1998. Toyota Production System: Beyond Large-Scale Production. OR: Productivity Press.

Ohno, K. 2014. Learning to Industrialize: From Given Growth to Policy-aided Value Creation. London: Routledge.

Ohno, I., K. Ohno, S. Uesu, A. Ishiwata, A. Hosono, T. Kikuchi, and T. Uenda. 2009. Introducing Kaizen in Africa. Tokyo: GRIPS Development Forum.

OICA. 2018. International Organization of Motor Vehicle Manufacturers, 2016 Production Statistics. http://www.oica.net/wp-content/uploads/ By-country.pdf

Senge, P.M. 1990. The Fifth Discipline: The Art and Practice of the Learning Organization. New York: Currency Doubleday.

Shimada, G. 2015. The Economic Implications of Comprehensive Approach to Learning on Industrial Development (Policy and Managerial Capability Learning): A Case of Ethiopia. In Industrial Policy and Economic Transformation in Africa, ed. Akbar Noman and Joseph Stiglitz, 102-122. New York: Columbia University Press.

Stiglitz, J.E., and B.C. Greenwald. 2014. Creating a Learning Society: A New Approach to Growth, Development, and Social Progress. New York: Columbia University Press.

Toyota. 2018a. Toyota Production System. http://www.toyota-global.com/company/vision_philosophy/toyota_production_system/

—. 2018b. The Official Blog of Toyota GB. http://blog.toyota.co.uk/ kaizen-toyota-production-system

- 2018c. Toyota traditions: Good Thinking, Good Products. http://www. toyota-global.com/company/toyota_traditions/quality/may_jun_2005.html

Toyota Jidōsha Kabushiki Kaisha. 1988. Toyota: A History of the First 50 Years. Toyota Motor Corporation.

Womack, J.P., D.T. Jones, and D. Roos. 1990. Machine that Changed the World: The Story of Lean Production. New York: Simon and Schuster.

Yan, B., and O.D. Makinde. 2011. Impact of Continuous Improvement on New Product Development Within SMEs in the Western Cape, South Africa. African Journal of Business Management 5 (6): 2220. 
Open Access This chapter is licensed under the terms of the Creative Commons Attribution 4.0 International License (http://creativecommons.org/licenses/ by $/ 4.0 /$ ), which permits use, sharing, adaptation, distribution and reproduction in any medium or format, as long as you give appropriate credit to the original author(s) and the source, provide a link to the Creative Commons licence and indicate if changes were made.

The images or other third party material in this chapter are included in the chapter's Creative Commons licence, unless indicated otherwise in a credit line to the material. If material is not included in the chapter's Creative Commons licence and your intended use is not permitted by statutory regulation or exceeds the permitted use, you will need to obtain permission directly from the copyright holder.

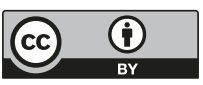

